\title{
OS QUATRO EVANGELHOS E O DIREITO CIVIL
}

THE FOUR GOSPELS AND CIVIL LAW

Antonio Junqueira de Azevedo*

\begin{abstract}
Resumo:
O texto pretende apresentar as posições evangélicas em temas de Direito Civil, - limitadas, neste primeiro artigo, às questões mais importantes sobre Pessoas e Bens da Parte Geral. As questões tratadas são: igualdade das mulheres, igualdade das etnias e nacionalidades; relações homossexuais e afetivas; início e fim da personalidade; animais e coisas.
\end{abstract}

Palavra-chaves: Evangelho. Igualdade. Discriminação. Animais.

\begin{abstract}
:
The text you want to display the Evangelical positions on matters of civil law - limited, in this first article, the most important issues regarding persons and property of the general part. The issues addressed are: women's equality, equality of ethnicities and nationalities; homosexual relations and affective; beginning and end of personality; animals and things.
\end{abstract}

Keywords: Gospel. Equality. Discrimination. Animals.

\section{Introdução}

Sem muito esforço, o leitor poderá imaginar a quantidade imensa de livros, comentando os Evangelhos, escritos nos últimos dois milênios, - especialmente nos vários idiomas da civilização ocidental, em grego, latim, português, francês, inglês, alemão, espanhol, italiano, etc. ${ }^{1}$ Poderá também imaginar o quanto já se publicou sobre Direito Civil nessas mesmas línguas: bibliotecas! No entanto, especificamente sobre os dois temas em conjunto, esse que é o nosso assunto, Evangelhos e Direito Civil, chega a ser surpreendente, mas não temos conhecimento de nenhum livro. Há, - e não são poucas -, obras sobre Religião e Direito; ${ }^{2}$ em geral, porém, examinam o direito à luz da religião - e, por outro lado, não se limitam, no campo jurídico, ao Direito Civil nem, no religioso, aos Evangelhos. Nosso intuito é diverso: pretendemos examinar somente os Evangelhos, e à luz do Direito Civil; ${ }^{3}$ por isso mesmo, o que se poderia chamar de "grade de exposição",

\footnotetext{
* $\quad$ Professor Titular de Direito Civil e ex-Diretor da Faculdade de Direito da Universidade de São Paulo.

1 "Evangelhos", em todo o texto desse artigo, são os evangelhos canônicos: de São Mateus (Mt), São Marcos (Mc), São Lucas (Lc) e São João (Jo).

2 Por exemplo, "Il diritto nel Vangelo" de Carlo Gray, 1922; "De l'influence du christianisme sur le droit civil des Romains", de Raymond Theodore Troplong, 1868 ( $3^{\mathrm{a}}$ ed.); as considerações de Gustav Radbruch sobre religião nos vários institutos tratados em "Filosofia do Direito"; etc.

3 Há algo parecido já feito em outros campos do direito; em direito processual e penal, por exemplo, por causa
} 
para este ensaio, será o quadro de direito civil como vem sendo ensinado no Brasil nos últimos séculos - é o quadro de origem pandetista -: uma Parte Geral, em três livros, dois, com os elementos da estática jurídica, pessoas e bens, e um terceiro, com os elementos da dinâmica jurídica, fatos jurídicos; e uma Parte Especial, em quatro livros, família, direitos reais, obrigações e sucessões. Este artigo, especificamente, por fraqueza humana, está limitado aos dois elementos da estática jurídica; o restante da matéria civilista fica, se houver disposição, para ser desenvolvido em outro texto.

\section{Pessoas Naturais}

Igualdade do homem e da mulher. O intenso papel das mulheres nas atividades de Jesus

Antes de mais nada cumpre salientar que é recente no mundo jurídico a norma da igualdade do homem e da mulher. Exemplificando, o Código Civil, que inaugura os tempos jurídicos atuais, o Código Civil francês, de 1804, no seu artigo 12, determinava que a estrangeira que tivesse casado com um francês seguia a condição do marido e, no art. 19, demonstrando que o problema não era de predominância da nacionalidade e sim, de predominância de sexo, determinava, inversamente, que a mulher francesa que casasse com um estrangeiro também seguia a condição do marido. Entre nós, o Código Civil de 1916, em sua redação originária, qualificava a mulher casada entre os relativamente incapazes! A igualdade somente veio, e não de maneira completa, com o Estatuto da Mulher Casada de 1962. Somente, pois, em meados do século XX, é que as idéias dos movimentos feministas acabaram vencendo preconceitos de superioridade masculina.

E os Evangelhos? Até hoje, as pessoas em geral, ainda que com boa cultura, não têm uma idéia clara do quanto as mulheres estavam presentes nas atividades de Jesus. Jesus, nas pregações pela Galiléia, Judéia e territórios próximos, se fazia acompanhar muitas vezes pelos apóstolos e por um grupo de mulheres. Está escrito; esses acompanhantes eram dos dois sexos. O Evangelho de São Lucas é claro (Lc 8, 2 e 3): "E aconteceu após isto que andava pelas cidades e aldeias pregando e anunciando o reino de Deus, e os doze estavam com ele, como também algumas mulheres que tinham sido livradas de espíritos malignos e enfermidades: Maria, chamada Madalena, da qual tinham saído sete demônios, e Joana, mulher de Cusa, procurador de Herodes, e Suzana e outras muitas, que o assistiam

do processo de Jesus: "Il processo a Gesù", S.G.F.Brandon, trad. it. de "The Trial of Jesus of Nazareth", 1968; "O Julgamento de Jesus, o Nazareno", de Haim Cohn,ex-presidente da Suprema Corte de Israel, trad. bras.; "Il caso Gesù. Il piú controverso processo della storia", de W. Fricke, trad. it., 1989; etc.). Mas poderia também haver o exame dos Evangelhos à luz do Direito Tributário, pelas várias referências a impostos (" $a$ César o que é de Cesar" e Mt 17, 24-27); idem, no Direito do Trabalho (e contratual) pela frequência com que nos Evangelhos se apresentam operários (inclusive a difícil parábola dos operários da vinha - Mt 20, 1-16); em Direito Constitucional, pela diversidade de estruturas políticas referidas; etc. 
com as suas posses". Mais adiante, por ocasião da via crucis, o mesmo Evangelho de São Lucas (Lc 23, 27-29) torna a referir a presença de mulheres: “Seguia-o, porém, uma grande multidão de povo e de mulheres que choravam e o lamentavam. Mas Jesus voltouse para elas e disse: "filhas de Jerusalém, não choreis sobre mim, chorai sobre vós mesmas e sobre vossos filhos". Ainda Lc 23, 49.

Também por ocasião da paixão, os outros três evangelhos relatam a presença das mulheres: "Achavam-se também ali, de longe, muitas mulheres, que desde a Galiléia tinham seguido e servido a Jesus. Entre elas estavam Maria Madalena, Maria, mãe de Tiago e José e a mãe dos filhos de Zebedeu" (Mt 27, 55). "E achavam-se ali também umas mulheres, observando de longe; entre as quais estavam, Maria Madalena, e Maria, mãe de Tiago o Menor e de José, e Salomé, que o tinham seguido e o haviam assistido, quando ele estava na Galiléia; e muitas outras que juntamente com ele haviam subido a Jerusalém" (Mc 15, 40). "Junto à cruz de Jesus, porém, estavam de pé sua Mãe, a irmã de sua Mãe, Maria, mulher de Cléofas, e Maria Madalena" (Jo 19, 25). ${ }^{4}$

Sem esquecer que a primeira pessoa a quem Cristo ressuscitado apareceu era uma mulher, Maria Madalena, interessa aqui, para a questão da igualdade entre homem e mulher, examinar o conhecido episódio da samaritana junto ao poço (Evangelho de São João 4, 4-42); esse fato revela, com antecedência de séculos e milênios, a igualdade ao mesmo tempo social e religiosa com que Jesus tratava a todos. No relato, os apóstolos de início não estão presentes e, quando chegam, se espantam que Jesus estivesse falando com uma mulher desconhecida. Esse não era um comportamento usual. O texto diz: " $\mathrm{E}$ logo os seus discípulos chegaram, e maravilharam-se de que estivesse falando com uma mulher. Ninguém, todavia, disse: - Que perguntas? - ou: Que falas com ela?". Além disso, observamos nós, o diálogo então travado entre Jesus e a samaritana consubstancia a revelação sobre a água da vida - tão importante para a obtenção do Reino de Deus - e essa revelação é feita a uma mulher. Em todos os quatro Evangelhos, vê-se, pois, uma profunda igualdade entre homem e mulher, igualdade anterior, de séculos e milênios, à norma jurídica do Ocidente atual. ${ }^{5}$

4 Como se vê, Maria Madalena tinha presença importante, porque está em todas as listas. Foi também a primeira pessoa a ver Cristo ressuscitado. Não há, porém, nada que indique, além de relações afetivas, também relações sexuais entre Jesus e Maria Madalena. Os evangelhos apócrifos é que trazem alguma coisa nesse sentido: "Evangelho de Felipe" (meados do século III provavelmente), logion 55 "a companheira do Filho é Miriam (Maria) de Magdala. O Mestre amava Miriam mais que a todos os discípulos; ele freqüentemente a beijava na boca". Em seguida, nesse texto, os apóstolos se queixam de revelações diretas feitas a uma mulher ("L'Evangile de Philippe", introd. e edição de Jean-Yves Leloup, Paris, Albin Michel, 2003, pg. 107). No também apócrifo "Evangelho de Maria Madalena" (texto 17), há a mesma afirmação de tratamento preferencial e, da mesma forma, há queixa - aqui, de Pedro - de revelação direta a uma mulher. ("The Gospel of Mary Magdalene”, Jean-Yves Leloup, trad. inglesa, Vermont, Inner Traditions, 2002, p. 159).

5 Se a igualdade entre homem e mulher prevalecia no movimento de Jesus e está nos Evangelhos, cumpre 
A igualdade (ou desigualdade) de nacionalidades e etnias

O Código Civil, de 1916, trazia artigo (o art. $3^{\circ}$ ) que era uma proclamação de igualdade das nacionalidades: "A lei não distingue entre nacionais e estrangeiros quanto à aquisição e ao gozo dos direitos civis". No Anteprojeto que serviu de base para o atual Código Civil, o artigo homólogo recebeu redação mais fraca: "Salvo lei em contrário, a lei não distingue entre nacionais e estrangeiros quanto à aquisição e ao gozo dos direitos civis" e foi, então, objeto da crítica de Caio Mário da Silva Pereira: "Logo no seu inicio eclode a tendência acanhada ou tímida de suas soluções. Quem confrontar os texto de 1916 e de 1972, estranha o que num e noutro se enuncia sobre a igualdade na aquisição e no exercício dos direitos civis. Enquanto o diploma vigente <é o de 1916> a enuncia corajosamente, proclamando que "a lei não distingue entre nacionais e estrangeiros quanto à aquisição e ao gozo dos direitos civis" (art. $3^{\circ}$ ), o anteprojeto faz uma restrição ao principio no art. $2^{\circ}$ : "Salvo lei em contrário, não se distingue entre nacionais e estrangeiros quanto à aquisição e ao gozo dos diretos privados". Meio século depois de um pronunciamento aberto e confiante, manifestar-se-ia o receio, a falta de fé, o pensamento restritivista. Compreende-se a cautela no tocante aos direitos políticos. Mas desafina da grandeza de nossa época, destoa do apelo que se faz à importação do capital e da técnica alienígena este preceito, como a dizer que os teremos aqui, mas em plano de desigualdade" (jornal "O Estado de São Paulo", 20/XII/72). Tornou-se essa norma um dos pontos do violento debate entre o mencionado jurista e o coordenador do novo texto civil, Miguel Reale. O artigo da igualdade acabou suprimido do Código Civil, eis que as desigualdades residuais eram antes de direito público que de direito privado. Com ou sem texto legal, prevalece, porém, no campo civilista, sem sombra de dúvida a igualdade geral das pessoas, inclusive entre nacionais e estrangeiros.

Nos Evangelhos, não é exatamente assim. Jesus era um bom judeu e, apesar das várias orientações do judaísmo de então (fariseus, saduceus, essênios, zelotas) e apesar da espiritualização da religião pelo movimento de Jesus, todas essas correntes religiosas

explicar por que ocorreu, na própria Igreja, a desigualdade posterior. Ora, em palavras simples, a causa é a formação judaica e greco-romana da população de então, inclusive, especialmente de São Paulo; por exemplo, I Co 11, 7-9: "O homem, certamente, não deve cobrir sua cabeça, porque é imagem e glória de Deus, mas a mulher é glória do homem. Nem foi o homem criado por causa da mulher, mas sim a mulher por causa do homem ". É preciso ter em mente que São Paulo, tão ativo na difusão e organização do cristianismo primitivo, na verdade, não foi apóstolo, um dos doze, e nunca viu nem ouviu o Jesus histórico. Em suas viagens, não se fazia acompanhar de mulher, ao contrário de São Pedro e outros. Ele mesmo escreveu (I Co 9, 3-6): "Esta é a minha defesa contra os que me examinam. Não temos nós porventura o direito de comer e beber? Acaso não temos nós o direito de levar uma mulher irmã, assim como também os outros apóstolos, e os irmãos do Senhor, e Cefas? Ou eu só e Barnabé não temos direito de fazer isto? ". Vê-se que as idéias de desigualdade de São Paulo não correspondem aos Evangelhos - e nem mesmo ao comportamento dos apóstolos, inclusive São Pedro (Cefas), que foi casado. 
ou ideológicas sustentavam que o Messias deveria nascer entre os judeus, o povo eleito, - sob esse aspecto, diverso dos demais. Essa prioridade está também nos Evangelhos, escrevendo São João Evangelista, literalmente, que "dos judeus é que vem a salvação" (Jo 4,22) (E há quem diga que esse Apóstolo, judeu ele mesmo, era anti-semita!) O próprio Jesus, segundo os Evangelhos, deu prioridade aos judeus. Um episódio interessante é o da mulher cananéia portanto, não-judia, que pediu a Jesus o favor de curar sua filha (Mt 15, 21 e Mc 7,24) e a quem Jesus respondeu que primeiramente deveria atender aos judeus - comparados a filhos -, e não aos gentios, - comparados a cães. A mulher cananéia, insistindo, replicou que também os cachorrinhos comem as migalhas que os meninos deixam cair da mesa. A humildade dessa imagem tocou a Jesus que, então, atendeu ao pedido. Percebe-se, do ponto de vista das nacionalidades e etnias, que há, pois, uma situação dúplice: prioridade histórica para os judeus, mas também atendimento posterior aos não-judeus. O mesmo poderia ser concluído das várias referências dos Evangelhos às populações de Tiro e Sidônia, cidades do Líbano, ou de Nínive e da Mesopotâmia, da Arábia, de Roma, etc. Em resumo, os Evangelhos não revelam preconceito de etnia ou nacionalidade; expressam somente a transição histórica: do mundo antigo ao mundo cristão. Há passagem da religião local à religião universal, e do judaísmo, pelo menos como era, ao "Ide, pois, e ensinai todas as nações" (Mt 28, 19).

Relações homossexuais e relações afetivas

Além das possíveis discriminações anteriormente examinadas - de gênero (homem - mulher), de nacionalidade e etnia -, é importante, nos tempos de hoje, verificar como os Evangelhos tratam a questão das relações homossexuais e das relações afetivas (sendo que por "relações afetivas" não estamos entendendo relações abstratas, meramente teóricas, mas sim, relações de amizade entre pessoas sem parentesco próximo e com algum envolvimento físico, isto é, com algum prazer na companhia recíproca - o que envolve os sentidos, contato, vista, ouvido -, embora sem relações sexuais. Ora, não há, nos Evangelhos, nenhuma palavra nem contra nem a favor das relações homossexuais e há, ao contrário, uma espécie de aprovação das relações afetivas quer entre pessoas do mesmo sexo quer entre pessoas de sexo diferente. Essa diferença de tratamento entre os dois tipos de relação justifica, até certo ponto, a distinção apresentada por Paulo VI (Cf. "Declaração sobre algumas questões de ética sexual", de 29 de dezembro de 1975, n. 8) entre homossexualismo como condição ou tendência e como ato ou atividade (a atividade é condenada - cf. "Catecismo da Igreja Católica”, n. 2357).

Na condenação do homossexualismo, que muitos textos da Igreja expressam, não há nenhuma que apresente fundamento nos Evangelhos. O fundamento é sempre ou o Antigo Testamento ou cartas de São Paulo. Ora, o Antigo Testamento, já se sabe, 
não é homogêneo e, nele, toda idéia exige interpretação cuidadosa porque vem sempre envolta em circunstâncias da cultura do tempo. O próprio trecho básico para manifestação condenatória na matéria ("não te deitarás com um homem, como se fosse mulher; isto é uma abominação" - Levítico, 18, 22) vem logo depois de outra prescrição, hoje nãoobrigatória na Igreja: "não te achegarás a uma mulher durante a sua menstruação". (Aliás, Levítico, capítulo 15, já havia posto a mulher nessas condições como "impura”). Uma proibição simples, - o homossexualismo é condenado -, sem qualquer esclarecimento e distinção de situação, parece, salvo melhor juízo, não corresponder nem mesmo ao texto transcrito, de Levítico 18, 22, e levaria a condenações sem fim, inclusive do rei Davi e de suas relações com Jônatas: "Tendo Davi acabado de falar com Saul, a alma de Jônatas apegou-se à alma de Davi e Jônatas começou amá-lo como a si mesmo" (I Samuel, 18, 15). Mais adiante, é Davi quem diz: "Jônatas, meu irmão, por tua causa meu coração me comprime! Tu me eras tão querido! Tua amizade me era mais preciosa que o amor das mulheres" (II Samuel 1, 26).

Por outro lado, quanto às condenações do homossexualismo por São Paulo (Rm 1, 24-27; I Co 6, 10; I Tm 1, 10), ${ }^{6}$ cumpre lembrar mais uma vez que 1) São Paulo não era apóstolo, um dos doze; 2) ele nunca viu, nem ouviu o Jesus histórico. Por isso mesmo, como já vimos sobre as mulheres e adiante veremos sobre os animais (supra nota 5 e infra nota 12), suas idéias sobre comportamento tem muito da orientação moral do tempo, e não de Jesus e dos Evangelhos - cujo fim, aliás, é religioso, o Reino, e não propriamente ético ou moral.

Se, porém, nada há nos Evangelhos contra ou a favor das relações homossexuais, há tudo a favor das relações afetivas - no sentido supra dito. Senão vejamos. São João Evangelista, a quem a tradição atribui uma vida longa e de muita pureza, era o "discípulo amado", "the beloved disciple": "Ora um dos discípulos, a quem Jesus amava, estava à mesa reclinado ao peito de Jesus. A este Simão Pedro acenou e lhe disse: "Quem é de quem ele fala?" Reclinando-se o mesmo sobre o peito de Jesus, pergunta-lhe: "Senhor, quem é?" Jesus respondeu: "É aquele a quem eu der o pão embebido". E depois que molhou o pão, deu-o a Judas, filho de Simão Iscariotes" (Jo 13, 23-26). E em outro trecho (Jo 21, 20-23): "Voltando-se Pedro, viu que o seguia aquele discípulo que Jesus amava, o qual estivera reclinado sobre o seu peito, durante a ceia, e lhe perguntara: "Senhor, quem é que te há de trair?" Vendo-o, pois, Pedro perguntou a Jesus: "Senhor, e este? Que será dele?" Jesus responde-lhe: "Quero que ele fique assim até que eu venha; que tens tu com isso? Segue-me tu!" Correu, pois, esse boato entre os irmãos: “Aquele discípulo não

\footnotetext{
Em Rm 1, 24—27, na verdade, o homossexualismo não é propriamente um ato condenado mas sim uma pena para os estultos que não glorificam a Deus.
} 
morre". Mas Jesus não lhe disse: "Não morre", mas: "Quero que ele fique assim até que eu venha; que tens tu com isso?".?

Também Lázaro, irmão de Marta e Maria (Jo 11, 1), era certamente muito querido por Jesus: “Quando, porém, Maria chegou aonde Jesus estava e o viu, lançou-se aos seus pés e disse-lhe: "Senhor, se houvesse estado aqui, meu irmão não teria morrido". Ora, vendo-a Jesus chorar, e chorarem os judeus que tinham vindo com ela, ficou intensamente comovido em espírito. E perguntou: “Onde o pusestes?” Responderam-lhe: "Senhor, vem e vê". E Jesus chorou. Disseram por isso os judeus "Vede como ele o amava" (Jo 11, 32-36).

As relações afetivas não tinham como pólo somente homens mas também mulheres; assim, “Ora, Jesus estimava Marta, Maria, sua irmã, e Lázaro” (Jo 11, 5). Provavelmente, entre as mulheres, deveria estar também Maria Madalena ${ }^{8}$. Finalmente, um sinal de que Jesus não era alheio à simpatia física, própria das "relações afetivas", encontra-se no episódio do jovem rico: "Mas olhando-o Jesus, quis-lhe bem e disse-lhe: "Uma só coisa te falta; vai, vende tudo o que tens e dá-o aos pobres, e terás um tesouro no céu; depois vem, e segue-me" (Mc 10, 20 e 21).

Fora dos atos e ditos de Jesus, há também a amizade que consta do relato do centurião romano, cujas palavras são usadas na missa ("Senhor, eu não sou digno de que entreis em minha morada"). As relações afetivas estão assim expressas: “Ora, o criado dum centurião, a quem este muito estimava, estava doente, às portas da morte. Quando pois, ouviu falar de Jesus, enviou-lhe alguns anciãos dos judeus, rogando-lhe que viesse e salvasse o seu criado" (Lc 7, 2 e 3; cf. também Mt 8, 5-13).

Em síntese, em matéria de "relações homossexuais", os Evangelhos estão aproximadamente como está hoje a legislação civil, numa posição neutra. Sobre relações afetivas, porém, os Evangelhos contêm narrações de aprovação, - embora essas relações pareçam não ser objeto idôneo para preceitos jurídicos, que sobre elas praticamente silenciam.

Nascituro. Início e fim da personalidade

$\mathrm{O}$ art. $2^{\circ}$ do atual Código Civil dispõe: “Art. $2^{\circ}$ A personalidade civil da pessoa começa do nascimento com vida; mas a lei põe a salvo, desde a concepção, os direitos do nascituro". Se a personalidade civil começa do nascimento com vida, percebe-

\footnotetext{
As pesquisas históricas parecem concordar, hoje, em que o capítulo 21 do Evangelho de São João é acréscimo posterior. Há também muitos teólogos que negam que a autoria de todo esse Evangelho seja de São João - com isso não concordamos, De qualquer forma, esse ponto tem importância menor porque o autor, nessa hipótese, seria alguém da "comunidade joanina", isto é, um dos fiéis instruídos por São João.

8 Vide nota 4 supra.
} 
se que o nascituro - embrião no ventre materno - não é civilmente pessoa, embora já possa ser sujeito de direito. A expressão "sujeito de direito" juridicamente é, pois, mais ampla que "pessoa". Entes, em processo de aquisição de personalidade, como as fundações já instituídas e ainda não registradas, podem ser sujeito de direito e ainda não tem personalidade civil; juridicamente é a mesma situação do nascituro. Essa solução jurídica, porém, não resolve a questão filosófica sobre ser o nascituro pessoa. Ora, perante os Evangelhos, ele é pessoa, porque, nos textos, ao nascituro já se denomina “criança”. Leiase, em belo trecho, o que está dito da visita de Maria à sua prima Isabel, ambas grávidas: "Naqueles dias, Maria se levantou e foi com pressa às montanhas, a uma cidade de Judá; e entrando em casa de Zacarias, saudou a Isabel. E aconteceu que, apenas Isabel ouvira a saudação de Maria, a criança saltou no seu ventre; e Isabel ficou cheia do Espírito Santo. E exclamou em alta voz, dizendo: "Bendita és tu entre as mulheres e bendito é o fruto do teu ventre. E donde me é concedido vir visitar-me a mãe do meu Senhor? Pois mal chegou a voz da tua saudação aos meus ouvidos, a criança saltou de alegria no meu ventre. $E$ bem aventurada és tu que creste, pois se hão de cumprir as coisas que pelo Senhor te foram ditas" (Lc 1, 39 a 45).

Quanto ao fim da personalidade, discutem juristas e médicos sobre o que melhor caracteriza a morte: a parada cerebral, a cardíaca, a respiratória, etc. Obviamente a preocupação “está morto?” não encontra resposta genérica nos Evangelhos mas, como curiosidade, lembramos que, naquele tempo, houve quem fizesse a mesma pergunta: " $\mathrm{E}$ quando já era tarde (pois era o parásceve, que vem a ser a véspera do sábado), veio José de Arimatéia, ilustre membro do sinédrio, que também esperava o Reino de Deus, e foi resoluto à presença de Pilatos, e pediu o corpo de Jesus. Pilatos, porém, admirou-se de que ele já tivesse morrido. E chamando o centurião, perguntou-lhe se já estava morto. Certificado, pois, disso pelo centurião, deu o corpo a José” (Mc 15, 42 a 45).

Bens

O evangelho da vida. Os animais não são coisas

Sobre o tema dos bens, o que há de mais atual, a nosso ver, é a valorização dos animais. $\mathrm{Na}$ formação civilista tradicional, os animais são considerados coisas (semoventes). Somente de 1990 para cá, por pressão de proprietários de cães, de alguns ecologistas e de intelectuais contrários à visão da soberania absoluta da espécie humana, houve alterações no mundo do direito; os códigos civis da Áustria, Suíça e Alemanha, foram alterados para fazer constar o óbvio, isto é, aquilo que, como escreveu Hans Jonas, 
qualquer dono de cachorro sabe: "os animais não são coisas". ${ }^{9}$ Infelizmente muita gente, inclusive alguns cristãos, - por preconceito, ou judaico, ou greco-romano, ou iluminista, ou todos juntos, - fazem radical separação entre homens e animais. Não é isto, como veremos, que está na pregação de Jesus e deflui dos textos evangélicos.

No judaísmo, na Bíblia (Gênesis 1, 26 e 28), a arrogância de "rei dos animais" está manifestada: "Então, Deus disse: "Façamos o homem à nossa imagem e semelhança. Que ele reine sobre os peixes do mar, sobre as aves dos céus, sobre os animais domésticos e sobre toda a terra, e sobre todos os répteis que se arrastam sobre a terra" (omissis) "Frutificai, disse ele, e multiplicai-vos, enchei a terra e submetei-a. Dominai sobre os peixes do mar, sobre as aves dos céus e sobre todos os animais que se arrastam sobre a terra". É verdade que a Bíblia (Antigo Testamento) não é um modelo de coerência; por exemplo, logo adiante, sobre o mesmo assunto, a serpente é antropomorficamente dita "o mais astuto de todos os animais" (Gênesis 3,1) e engana o todo-poderoso casal reinante (Adão e Eva).

Por sua vez, textos filosóficos antigos, não-judaicos, também afirmam a radical diferença entre homens e animais. ${ }^{10} \mathrm{E}$ até os "sábios" modernos, no seu racionalismo europocêntrico, participam da mesma opinião; é conhecida a polêmica de Descartes e Montaigne sobre noção do animal-máquina. ${ }^{11}$

Nos Evangelhos, entretanto, Deus, revelado por Jesus, se preocupa com todos os pequeninos, inclusive com os animais, a começar com os passarinhos: "Portanto vos digo: Não sejais cuidadosos da vossa vida, pelo que comereis, nem do vosso corpo, pelo que vestireis. Não é a vida mais do que o alimento, e o corpo mais do que o vestuário? Vede as aves do céu, pois que não semeiam, nem ceifam, nem recolhem nos celeiros; todavia vosso Pai celestial alimenta-as" (Mt 6, 25-26). ${ }^{12}$

Há uma espécie de vitalismo que percorre os Evangelhos nas várias referências a animais, quer "bons" quer "maus": corvos, pombas, raposas, lobos, peixes, serpentes, etc. mas principalmente há um terno vitalismo nas inúmeras citações dos animais domésticos.

9 BGB, § $90-\mathrm{A}:$ "Os animais não são coisas. Eles são protegidos por leis especiais. A eles se aplicam as regras vigentes para as coisas, se não houver disposição diversa". No Brasil, esperemos que o Código Civil também seja alterado. O livro de Hans Jonas é: "Le príncipe responsabilité", trad. fr., Paris, Flammarion, 1990. Entre os escritores brasileiros, lembramos Simone Eberle ("Deixando da Sombra dos Homens", (tese), Belo Horizonte, 2006. Daniel Braga Lourenço ("Direito dos Animais", Sérgio Fabris Editor, Porto Alegre, 2008 e os organizadores do livro "A Dignidade da Vida e os Direitos Fundamentais Para Além dos Humanos", Molinaro et alii, Ed. Fórum, Belo Horizonte, 2008.

10 Por exemplo, Cícero no De officiis, Livro I.

11 Cf. Thierry Gontier, "De l'homme à l'animal", Paris, Vrin, 1998, passim.

12 De novo, as idéias de São Paulo não são iguais - são contrárias - às acima transcritas dos Evangelhos. Na Primeira Carta aos Coríntios, lê-se: "Pois na lei de Moisés está escrito: "Não atarás a boca ao boi que debulha”. Acaso cuida Deus dos bois? Não é antes por nós que ele diz isto?” (I Co 9, 9-10). 
O jumento, para começar, é elevado à condição de trono para o Rei dos Reis: “Quando, pois, se aproximaram de Jerusalém e de Betânia, perto do monte das Oliveiras, enviou dois dos seus discípulos, dizendo-lhes: Ide à aldeia que está de fronte de vós, e, logo que entrardes nela, achareais preso um jumentinho, em que não montou ainda homem algum; desprendei-o e trazei-o. (omissis) E conduziram o jumentinho a Jesus; e cobriramno com os seus mantos, e ele montou no mesmo. Ora, muitos estenderam os seus mantos no caminho; outros, ainda, cortavam ramos das árvores, e espalhavam-nos pelo caminho. Tanto os que precediam como os que iam atrás clamavam, dizendo: "Hosana; bendito o que vem em nome do Senhor; bendito o reino, que vem, de nosso pai David, hosana nas alturas". (Mc 11, 1-10).

Os cachorros são citados em pelo menos três circunstâncias: uma, no episódio já referido da mulher cananéia, - episódio contado duplamente, Mt 15, 26-28 e Mc 7 24-30 - ; uma segunda vez, na parábola do rico epulão (Lc. 16, 21), quando os cães vem lamber as chagas do mendigo Lázaro, deitado à porta do rico; e uma terceira vez no sermão da montanha (Mt 7,6), como orientação para não dar aos cães o que é santo.

Os porcos também são citados pelo menos três vezes: uma na recomendação, que se tornou máxima popular, de que não se devem dar pérolas aos porcos (Mt 7,6); outra, no episódio de abrigarem demônios e se precipitarem no mar em Gérasa(Mc 5, 1-20) - episódio repetido em Mateus e Lucas (Mt 8, 28-34 e Lc 8, 26-39) - ; e uma terceira, como objeto de cuidados do filho pródigo (Lc 15, 15).

A galinha é modelo de mãe extremosa (Mt 23, 37 e Lc 13, 34): “Jerusalém, Jerusalém, que matas os profetas, e apedrejas os que te são enviados, quantas vezes quis ajuntar os teus filhos, como a galinha agasalha os seus pintainhos debaixo das asas, mas tu não o quiseste". O galo marca o tempo final das três negações de São Pedro: "E Pedro lembrou-se, da palavra que Jesus lhe havia dito: 'Antes que o galo cante duas vezes, três vezes me negarás'. E começou a chorar” (Mc 14, 72) (também Mt 26, 75).

Mas, de todos os animais, os mais lembrados são as ovelhas e carneiros. Esses ora ilustram parábolas ou fatos (Mt 18, 10; Lc 2, 8; Jo 2, 14) ora, em linguagem figurada e com o nome no plural ou no substantivo coletivo ("rebanho"), são metáforas para nós mesmos (Mt 12, 11; 15, 26; Lc 12, 32; Jo 21, 15-18; etc) e ora, finalmente, com a palavra no singular, são imagens do próprio Jesus, o "cordeiro de Deus" (Jo 1, 29-35). Nesse caso, Jesus não deixa também de ser o bom pastor: "Eu sou o bom pastor. O bom pastor dá sua vida pelas ovelhas. O mercenário, porém, e que não é pastor, a quem não pertencem as ovelhas, quando vê o lobo vir, abandona as ovelhas e foge; e o lobo rouba e dispersa as ovelhas. O mercenário, porém, foge, porque é mercenário e não se importa com as ovelhas. Eu sou o bom pastor; conheço as minhas e as minhas me conhecem a mim, como meu Pai me conhece e eu conheço o Pai; e dou a minha vida pelas ovelhas" (Jo 10, 11-15). 
Finalmente, cumpre lembrar que uma das imagens de Jesus com animais, bem enraizada no mundo católico, é a do menino Jesus no presépio, tendo de cada lado o boi e o burrinho. Essa figuração, na verdade, não está, porém, nos Evangelhos; sua primeira aparição escrita está em evangelho apógrifo, dito "Pseudo-Mateus", do séc. VI" . A meu ver, a força da imagem do presépio resulta de sua profunda correspondência ao amor à vida, que revelam a pregação de Jesus e os textos evangélicos. É o evangelho da vida. Em interpretação ampla, é o que diz São João Evangelista sobre o Cristo vivo (Prólogo do Verbo - Jo 1, 4): "Tudo foi feito por ele, e nada do que tem sido feito se fez sem ele. Nele estava a vida, e a vida era a luz dos homens".

São Paulo, outubro de 2009.

\section{Referências}

Todos os textos evangélicos foram citados conforme a 4. ed. do Novo Testamento, da Editora Vozes, 1950, trad. e anotado por Frei João José Pedreira de Castro O. F. M.

BRANDON, S. G. F. Il processo a Gesù. Tradução italiana de The Trial of Jesus of Nazareth. Milão: Ed. Di Comunità, 1968.

\section{CATECISMO DA IGREJA CATÓLICA.}

CÍCERO. De Officiis, Livro I.

COHN, Haim. O julgamento de Jesus, o Nazareno. Tradução brasileira. Rio de Janeiro: Imago, 1990 .

EBERLE, Simone. Deixando a sombra dos homens. (tese), Belo Horizonte, 2006.

FRICKE, W. Il caso Gesù. Il piú controverso processo della storia. Tradução italiana 1989.

GONTIER, Thierry. De l'homme à l'animal. Paris: Vrin, 1998.

GRAY, Carlo. Il diritto nel Vangelo. Ed. Anastatica, (1922), Roma, L'Erma di Bretschnei, 1972.

JONAS, Hans. Le principe responsabilité. Tradução francesa. Paris: Flammarion, 1990.

LELOUP, Jean-Yves. The Gospel of Mary Magdalene. Tradução inglesa. Vermont: Inner Traditions, 2002.

LELOUP, Jean-Yves L'Evangile de Philippe. Paris: Albin Michel, 2003.

13 No Evangelho Pseudo-Mateus, texto XIV, se lê "ali reclinou o menino em um presépio e o boi e o burro o adoraram". O texto continua fazendo referência a Isaias 1, 3: "O boi conheceu o seu dono e o burro, o presépio de seu senhor" (cf. "Los evangelios apócrifos", Aurélio de Santos Otero, Madri, 1979, p. 211). 
LOURENÇO, Daniel Braga. Direito dos animais. Porto Alegre: Sérgio Fabris Editor, 2008.

MOLINARO, Carlos Alberto; MEDEIROS, Fernanda L. F. de; SARLET, Ingo Wolfang e FENSTERSEIFER, Tiago. A dignidade da vida e os direitos fundamentais para além dos humanos. Belo Horizonte: Editora Fórum, 2008.

PEREIRA, Caio Mário da Silva. Entrevista. O Estado de São Paulo, São Paulo, 20/XII/72.

RADBRUCH, Gustav. Filosofia do direito. 6. ed. Coimbra: Armênio Amado, 1997.

REALE, Miguel. Entrevista. O Estado de São Paulo, São Paulo, 30/XII/72.

SANTOS OTERO. Los evangelios apócrifos. Madri: Bac, 1979.

TROPLONG, Raymond Theodore. De l'influence du christianisme sur le droit civil des Romains. 3. ed. Paris, 1868. 